\title{
Commercial or Non-CTEP IND Agent
}

National Cancer Institute

\section{Source}

National Cancer Institute. Commercial or Non-CTEP IND Agent. NCI Thesaurus. Code C38471.

An investigational new drug that does not come from the CTEP program. 